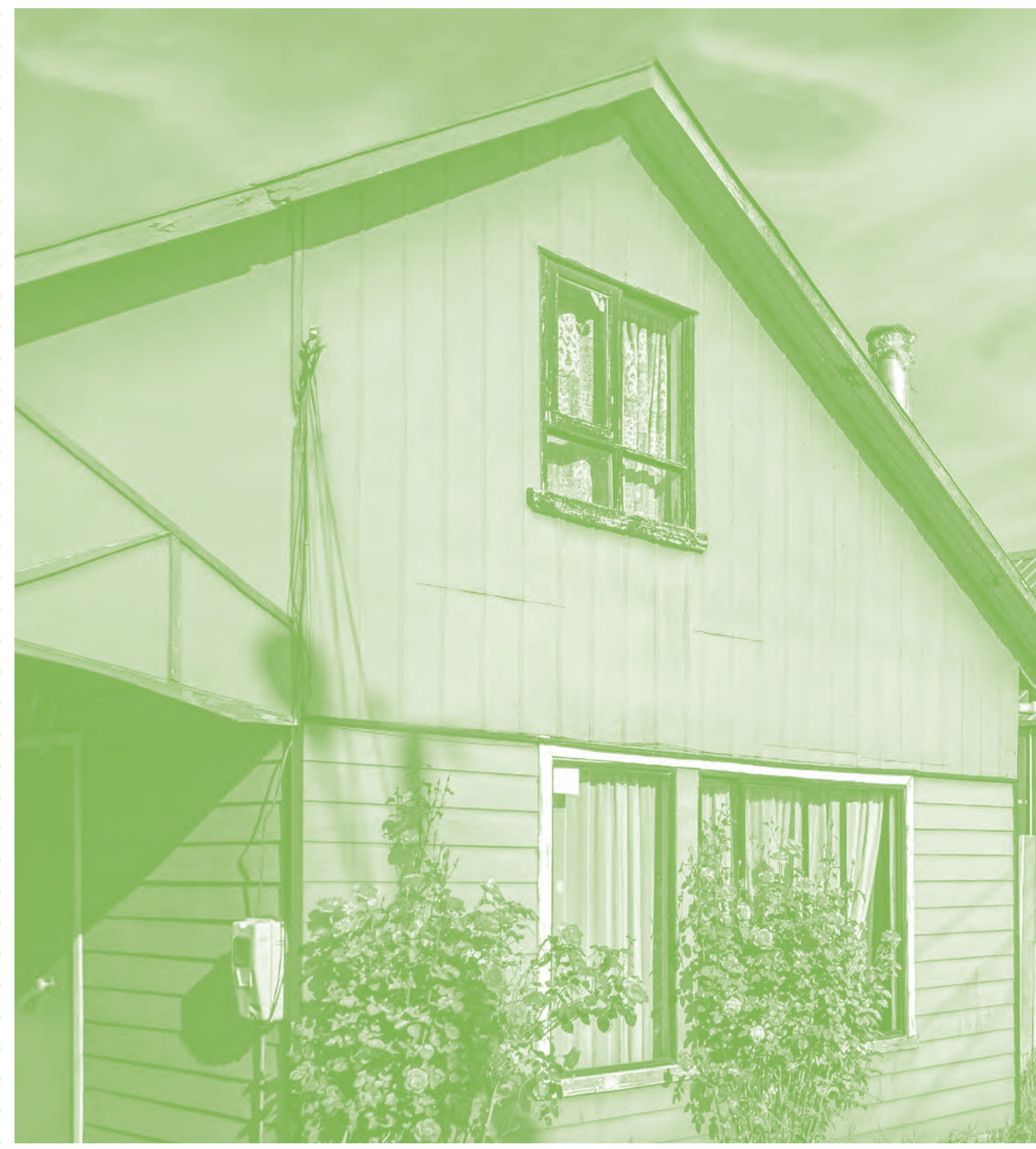




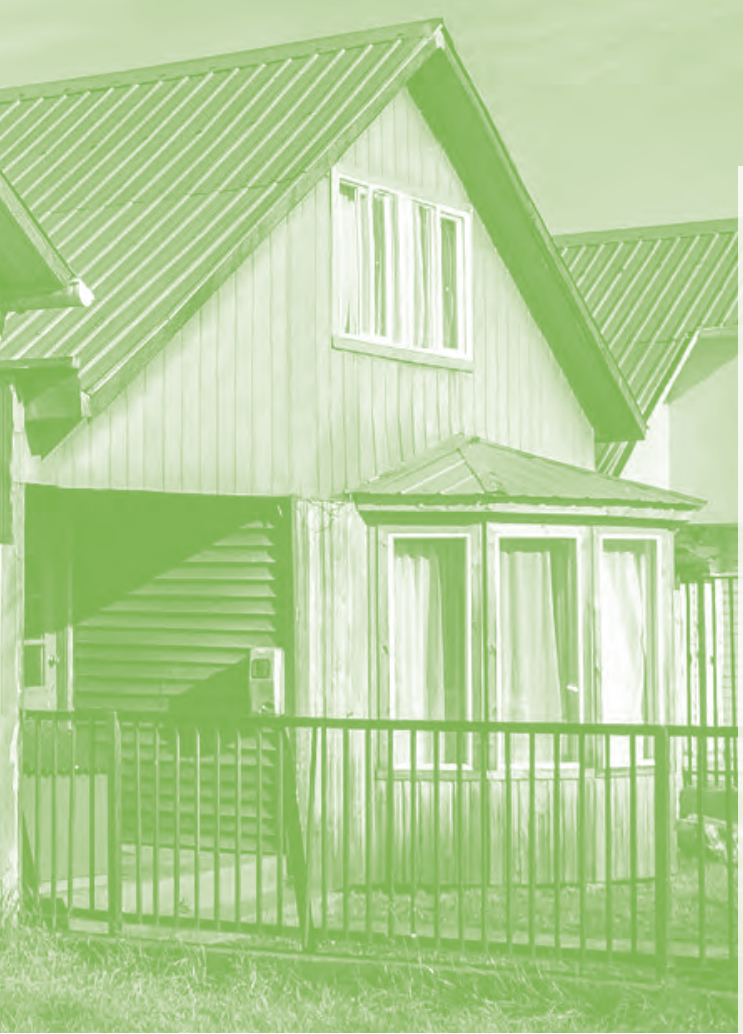

- artículo .

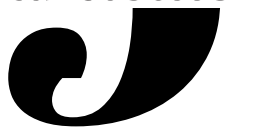

\title{
Tomando el derecho a una vivienda adecuada en serio en la próxima constitución chilena: Un derecho en construcción desde cero
}

Dr. Koldo Casla ${ }^{158}$ y Verónica Valenzuela ${ }^{159}$

DOI: $10.53110 /$ TINZ5472

\begin{abstract}
A. Introducción: Este capítulo introduce el derecho a una vivienda adecuada como parte del derecho a una vida digna. La primera sección presenta el contenido y alcance de este derecho a la luz del derecho internacional y derecho comparado. A continuación, el capítulo explora algunas implicaciones jurídicas y políticas en el mejoramiento de la situación del derecho a una vivienda adecuada en la futura constitución chilena, específicamente en relación con las responsabilidades de las inmobiliarias, el reconocimiento legal de la función social de la vivienda y la propiedad, y la necesidad de proteger a los arrendatarios con firmes condiciones de habitabilidad y seguridad de la tenencia en el sector privado de arriendos. Tomarse el derecho a la vivienda en serio como parte del derecho a un nivel de vida adecuado contribuye a enfrentar las causas estructurales de la pobreza y la desigualdad en Chile.
\end{abstract}

158 Profesor, Escuela de Derecho y Centro de los Derechos Humanos, Universidad de Essex, Reino Unido.

159 Maestría en Derechos Humanos Internacionales, Universidad de Essex y abogada litigante en la Unidad Programa de Derecho Humanos, Subsecretaría de los Derechos Humanos, Chile. 
B. El artículo 25 de la Declaración Universal de Derechos Humanos proclama

El derecho a una vivienda adecuada como parte del derecho a una vida digna: Una mirada al derecho internacional y la práctica comparativa en su primer párrafo que "toda persona tiene derecho a un nivel de vida adecuado que le asegure, así como a su familia, la salud y el bienestar, y en especial la alimentación, el vestido, la vivienda, la asistencia médica y los servicios sociales necesarios; tiene asimismo derecho a los seguros en caso de desempleo, enfermedad, invalidez, viudez, vejez u otros casos de pérdida de sus medios de subsistencia por circunstancias independientes de su voluntad".

El derecho a una vivienda adecuada es, en este sentido, parte del derecho a un nivel de vida adecuada. Está reconocido en el artículo 11(1) del Pacto Internacional de Derechos Económicos, Sociales y Culturales, artículo 27(4) de la Convención sobre los Derechos del Niño, artículo 5(e) del Convención Internacional sobre la Eliminación de todas las Formas de Discriminación Racial y artículo 14 de la Convención sobre la Eliminación de Todas las Formas de Discriminación Contra la Mujer. Todos estos tratados han sido firmados y ratificados por Chile, por lo tanto, el país debe acatarlos de buena fe como un asunto de derecho internacional.

De conformidad con el artículo 34 de la Carta de la Organización de los Estados Americanos, los países acuerdan esforzarse por lograr "una vivienda adecuada para todos los sectores de la población".

En Europa, el artículo 31 de la Carta Social Europea Revisada de 1996 proclama el derecho a una vivienda adecuada. El Comité Europeo de Derechos Sociales supervisa el cumplimiento de los Estados con la Carta Social Europea, en sus distintas versiones y con sus protocolos adicionales. Entre otras cosas, este comité ha establecido que la protección legal, social y económica de las familias incluye una provisión adecuada de vivienda, la que se extiende a la protección sobre desahucios ilegales, donde las reglas de procedimiento no han sido respetadas o donde los derechos de las personas afectadas no son suficientemente protegidos. ${ }^{160}$

Aunque no esté explícitamente mencionado en la Carta Africana de Derechos Humanos y de los Pueblos (Carta de Banjul), la Comisión Africana de Derechos Humanos y de los Pueblos ha interpretado que el derecho a una vivienda adecuada está implícito en la Carta Africana, ya que la esencia de ese derecho se deduce de otros derechos reconocidos en ésta, tales como el derecho a la salud, a la protección de la familia y el derecho de propiedad. ${ }^{161}$

El derecho a una vivienda está ciertamente vinculado con el derecho a la intimidad y vida familiar y el correspondiente derecho a la protección del domicilio. También proclamado en la Constitución de 1980 (artículos 19(4) y 19(5)), el derecho a una vivienda debe ser interpretado a la luz del derecho

${ }^{160}$ Comité Europeo de Derechos Sociales, 2004, pár. 24 y 51.

${ }^{161}$ Comisión Africana de Derechos Humanos y de los Pueblos, 2002, pár. 60. 
internacional de los derechos humanos, incluyendo el artículo 17 del Pacto Internacional de Derechos Civiles y Políticos, también ratificado por Chile. Al interpretar esta disposición, el Comité de Derechos Humanos de la Organización de Naciones Unidas (ONU) ha establecido que la prohibición de "injerencias arbitrarias" en el disfrute de nuestra vivienda "pretende garantizar que incluso cualquier injerencia prevista en la ley esté en consonancia con las disposiciones, los propósitos y los objetivos del Pacto y sea, en todo caso, razonable en las circunstancias particulares del caso". ${ }^{162}$

La vivienda es mucho más que un techo y mucho más que un simple producto. La vivienda, como observa el Comité de Derechos Económicos, Sociales y Culturales (el Comité DESC) de la ONU, debe "considerarse más bien como el derecho a vivir en seguridad, paz y dignidad en alguna parte". 163 El Comité DESC ha identificado siete requisitos para determinar si una vivienda es adecuada: a) seguridad jurídica de la tenencia, incluyendo la protección de desahucios forzosos, independientemente de del tipo de propiedad y duración (propietario, arrendatario, asentamiento irregular, etc.); b) disponibilidad de servicios, materiales, instalaciones e infraestructura, incluyendo el acceso a recursos naturales esenciales para la salud, seguridad, comodidad y nutrición; c) asequibilidad, incluyendo protección contra los niveles de renta desproporcionados, para así no dificultar o poner en peligro el cumplimiento y disfrute de otras necesidades y derechos esenciales; d) habitabilidad, en términos de protección del frío, humedad, calor, lluvia, viento y otras amenazas para la salud y la seguridad; e) accesibilidad, prestando particular atención a los requisitos de un colectivo o persona en riesgo, discriminación y marginación; f) una localización que permita el acceso a un empleo, a servicios médicos, escuelas, transporte y otras instalaciones, teniendo en cuenta también los problemas medioambientales; y g) adecuación cultural, usando materiales y herramientas que reconozcan y expresen apropiadamente la identidad cultural y la diversidad de la población. ${ }^{164}$

La práctica comparativa internacional demuestra que el progreso respecto al derecho a una vivienda adecuada puede resultar en políticas específicas que mejoren las condiciones de vida, particularmente de las personas en estado de vulnerabilidad. Comenzando por la evaluación de proporcionalidad, por ejemplo, en Escocia la ley distingue los motivos para el desahucio como obligatorio o discrecional, y en este último caso el propietario debe probar que ciertas circunstancias justifican el desahucio, por lo cual un juez decidirá la necesidad del desalojo, que podrá autorizar a partir del análisis de esas circunstancias. ${ }^{165}$ Igualmente, tanto Alemania como los Países Bajos, conceden a los

${ }^{162}$ Comité de Derechos Humanos de la ONU, 1988, pár. 4.

163 Comité DESC, 1991, p. 7.

164 Ibíd., pár. 8

165 Private Housing (Tenancies) (Escocia) Ley 2016. 
jueces el poder y la responsabilidad de prestar atención a las circunstancias personales de los arrendatarios, tomando en cuenta sus intereses legítimos junto a los del propietario. ${ }^{166}$

En el caso de Inglaterra, la Homelessness Reduction Act 2017 (Ley de la Reducción de la falta de hogar del 2017), en vigor desde abril del 2018, otorga a las autoridades más responsabilidades de las que ya existían desde 1970; Escocia y Gales cuentan con leyes similares. La normativa en el Reino Unido exige que los servicios sociales de las autoridades locales evalúen las causas y contextos en los que se puede presentar un potencial caso de pérdida del hogar, incluyendo las circunstancias y necesidades del núcleo familiar, particularmente si hay niños y/o niñas. Las autoridades locales deben intervenir con al menos 56 días de antelación al día en que pueda ocurrir la pérdida del hogar como resultado de un desahucio. Los servicios sociales pueden ofrecer ayuda económica para pagar el arriendo o pueden buscar viviendas alternativas en el sector inmobiliario público o privado de la zona. ${ }^{167}$

Entre el 2013 y 2017, muchas regiones en España reformaron sus leyes sobre vivienda para incluir incentivos fiscales y/o medidas sancionatorias dirigidas a propietarios con viviendas mantenidas vacías deliberadamente por un largo período de tiempo. Las nuevas normativas en esas regiones establecen que la propiedad de la vivienda debe servir la función social de satisfacer la necesidad de un hogar. Por lo tanto, las viviendas que se mantienen fuera del mercado no cumplen con el contenido legal esencial de la propiedad. ${ }^{168} \mathrm{El}$ Tribunal Constitucional Español concluyó que esas leyes autonómicas (regionales) eran un instrumento justo y admisible constitucionalmente para desarrollar el derecho a una vivienda adecuada, respetando al mismo tiempo el derecho a la propiedad privada, estando ambos derechos reconocidos en la Constitución española de 1978. ${ }^{169}$

En cuanto a la igualdad y la no discriminación, principios fundamentales del derecho internacional de los derechos humanos, hay dos ejemplos que conviene nombrar. A la luz del derecho internacional comparado y su práctica, en junio del 2020, la Suprema Corte de México exigió al Instituto Nacional de Estadísticas generar y recopilar información desglosada sobre la población viviendo en asentamientos irregulares. La Suprema Corte observó que estos datos darían una mejor información sobre el grado de pobreza en esos

\footnotetext{
166 Vols, Kiehl y Sidoli del Ceno, 2015, p. 2.

167 Ley de Vivienda de 1996, Parte VII: Homelessness, modified by Homelessness Reduction Act 2017.

168 Tribunal Constitucional español, Sentencias 93/2015 (Fundamento Jurídico n. ${ }^{\circ}$ 13), 16/2018 (Fundamento Jurídico n. ${ }^{\circ}$ 5) y 32/2019 (Fundamento Jurídico n. $\left.{ }^{\circ} 7\right)$.

169 Tribunal Constitucional español, Sentencia 16/2018 (Fundamento Jurídico n. $\left.{ }^{\circ} 17\right)$
} 
asentamientos y el impacto que puede tener en la población la asignación de recursos públicos y otras ayudas. ${ }^{170}$ Por su parte, el artículo 149 de la Ley de Igualdad del 2010 del Reino Unido, vigente en Gales, Escocia e Inglaterra, requiere que las autoridades públicas tengan en consideración la necesidad de eliminar la discriminación, acoso y victimización, fomenten la igualdad de oportunidades y promuevan buenas relaciones. Los órganos judiciales o cuasi-judiciales que monitorean el cumplimiento de esta obligación normalmente requieren información desglosada con miras a eliminar la discriminación directa e indirecta.

La implementación de políticas específicas en las últimas cuatro décadas en todo el mundo provocó la caída en la inversión pública en vivienda, la privatización de la vivienda pública, la liberación del sector de la construcción y "creciente función y la posición dominante sin precedentes de los mercados financieros y las empresas en el sector de la vivienda", dando como resultado la desconexión entre la vivienda y su función social, tratándola fundamentalmente como un activo financiero. ${ }^{171}$ La mercantilización de la vivienda, es decir, tratar la vivienda como un producto y no como un derecho, ha tenido significantes consecuencias en Chile. En esta sección trataremos algunas de ellas.

\section{i. El Estado y los promotores inmobiliarios privados: Los compo- nentes de la desigualdad}

La vivienda no es sólo un derecho humano; también es el espacio físico donde las personas desarrollan su propia personalidad, donde las familias crecen y comparten su vida. El derecho a la vivienda está profundamente vinculado con otros derechos humanos. La localización de una vivienda afecta muchos otros derechos y servicios, incluyendo la educación, empleo y salud. 172

Chile enfrenta niveles extremos de "desigualdad económica y social", ${ }^{173}$ ya que el ingreso promedio del 10\% de la población rica es 27 veces más que el 10\% de la población pobre, excediendo notablemente el promedio de los países de la Organización para la Cooperación y el Desarrollo Económicos (OCDE). ${ }^{174}$ El coeficiente de Gini en Chile en 2017 (últimos datos disponibles) era
C.

Constituciona ${ }^{-}$ lizar el derecho a una vivienda adecuada en Chile: Lo que puede significar en la práctica

Suprema Corte de México, 2020.

171 Asamblea General de Naciones Unidas, 2017, pár. 1.

172 Asamblea General de Naciones Unidas, 2018, pár. 32

173 Asamblea General de Naciones Unidas, 2016, pár. 13.

174 Chapman, 2016, p. 87. 
de 0.47 , posicionando al país entre los más desiguales dentro de la OCDE. ${ }^{175}$ El anterior Relator Especial de las Naciones Unidas sobre la Extrema Pobreza y Derechos Humanos, Philip Alston, observó que desde un punto de vista geográfico, Chile vive "grandes diferencias entre las regiones y dentro de las ciudades";176 personas viviendo en la misma área sufren grandes diferencias en sus niveles de ingreso.

En el caso de Chile, es innegable la relación entre políticas públicas sobre vivienda y la desigualdad estructural. Leilani Farha, anterior Relatora Especial sobre la Vivienda Adecuada, señaló que una serie de circunstancias históricas han motivado a que el país viva una "segregación geográfica de la población por niveles socioeconómicos, de modo que quienes cuentan con menos recursos viven en las afueras de las ciudades o en condiciones precarias". ${ }^{177}$

El capítulo III de la actual Constitución consagra el derecho a la protección de la salud, el derecho y la libertad de educación y el derecho a la seguridad social; sin embargo, en "comparación con los tratados internacionales sobre la materia, los derechos sociales fundamentales se encuentran débilmente consignados en la Constitución chilena de 1980", 178 tanto con el contenido de los derechos como en el mecanismo de rendición de cuentas de las autoridades. El derecho a una vivienda adecuada no está cubierto en la Carta de Derechos constitucional. La mayoría de los derechos sociales protegidos por los instrumentos internacionales de derechos humanos "no está cabalmente resguardada o definida en el catálogo de derechos fundamentales" en Chile. ${ }^{179}$ El borrador de derechos humanos constitucionales fue efectuado "en el contexto de la política radical de privatización de los beneficios sociales impulsada por Pinochet". ${ }^{180}$ Así, muchos beneficios relacionados con los derechos sociales, en gran medida, son proporcionados por empresas privadas mientras que el Estado juega un papel subsidiario.

A pesar de la carencia de arraigo constitucional del derecho a una vivienda adecuada, la anterior Relatora Especial sobre vivienda admitió que "Chile ha logrado reducir sustancialmente su déficit de vivienda en términos cuantitativos y, en cierta medida, también cualitativos, y ha puesto en marcha programas para diversificar los sistemas de tenencia”. ${ }^{181}$ Sin embargo, Chile es una de las principales "economías privatizadas" en Latinoamérica y ha dependido de manera desproporcionada del mercado inmobiliario privado, "en que el Es-

\footnotetext{
175 OECD, sin fecha.

176 Op. Cit., Asamblea General de Naciones Unidas, 2016, pár. 14.

177 Op. Cit., Asamblea General de Naciones Unidas, 2018, pár. 21.

178 Bustos, 2015, p. 229.

179 Schönsteiner et al., 2016, p. 7.

180 Lovera, 2010, p. 226.

181 Op. Cit., Asamblea General de Naciones Unidas, 2018, pár. 18.
} 
tado desempeña una función subsidiaria”. ${ }^{182}$ Así, las políticas públicas encargadas de la provisión de viviendas han sido desarrolladas en base al mercado privado y "su exclusivo vínculo con la propiedad privada". ${ }^{183}$ Tal estructura ha mostrado ser infructuosa en el cumplimiento del derecho a una vivienda adecuada según los estándares internacionales de derechos humanos.

El Estado Chileno ha financiado el mercado inmobiliario privado mediante subsidios públicos, de tal forma que los "principales actores en el sector de la vivienda son los constructores privados, los promotores inmobiliarios y las instituciones financieras, que cuentan con gran influencia". ${ }^{184}$ Las promotoras y empresas de construcción compran tierras a bajo precio, localizadas en las afueras de la ciudad para maximizar ganancias. Las familias y personas de bajos recursos, y otros grupos vulnerables sólo pueden acceder a viviendas en la periferia. Como otros países de la región y en todo el mundo, las políticas públicas de vivienda en Chile reflejan el "abandono por los Estados de los programas de vivienda social y la mayor dependencia de las soluciones ofrecidas por el mercado privado". 185

A través de las políticas de subsidios a la vivienda, Chile puede haber profundizado la discriminación, segregación y marginación de grupos vulnerables, como las personas pobres, las personas migrantes, los pueblos originarios y las mujeres. Como señaló la Relatora Especial de la ONU sobre la Vivienda Adecuada, un modelo así "constituye un incentivo para la segregación, ya que sigue promoviendo la concentración de viviendas subsidiadas en terrenos baratos, generalmente situados en la periferia de las ciudades, sin servicios ni oportunidades de empleo". ${ }^{186}$ Esta política pública ha tendido a discriminar a algunos grupos vulnerables que tienen acceso limitado a los subsidios de vivienda.

El contexto chileno en materia la vivienda plantea cuestiones acerca de la medida en que el mercado privado, en sí mismo, pueda proveer los recursos y mecanismos necesarios para satisfacer el acceso a una vivienda adecuada. Actualmente Chile "carece de directrices para una política nacional de planificación urbana basada en los derechos humanos", 187 lo que perjudica aún más el cumplimiento del derecho a una vivienda adecuada toda vez que la ausencia de guías con enfoque en derechos humanos "parece haber originado fragmentación e incoherencias en los procesos de adopción de decisiones con respecto a la tierra, creando poderosos incentivos para que algunos gobiernos

\footnotetext{
Ibíd., pár. 23.

Silva et al., 2020, p. 30.

184 Op. Cit., Asamblea General de Naciones Unidas, 2018, pár. 24.

185 Op. Cit., Asamblea General de Naciones Unidas, 2017, pár. 10.

186 Op. Cit., Asamblea General de Naciones Unidas, 2018, pár. 29- 30.

187 Ibíd., pár. 34.
} 
locales prefieran una concentración de residentes de altos ingresos". 188 El actual paradigma sobre la vivienda requiere urgente revisión, ya que convierte a la vivienda en una mercancía, despojándola de su condición de derecho humano.

La constitucionalización del derecho a una vivienda adecuada ayudará a reducir la desigualdad material en Chile. No obstante, el reconocimiento constitucional de los derechos no es suficiente. El Estado debe adoptar otras medidas prácticas para asegurar el cumplimiento de este derecho. Se requiere un papel activo y compromiso del Estado para abordar las causas principales de la segregación en la vivienda, incluyendo la provisión pública de la vivienda para las personas que no pueden pagarlo por sí mismas en el sector privado y el reconocimiento de la función social de la propiedad.

\section{ii. La función social del derecho a la propiedad}

El artículo 19 N$^{\circ} 24$ de la Constitución de 1980 garantiza el derecho a la propiedad privada. También, establece que sólo la ley puede establecer "Iimitaciones y obligaciones que deriven de su función social", la que incluye el interés general de la nación, la seguridad nacional, las utilidades y la salud pública, y la conservación del medioambiente.

Mientras la Constitución establece la función social como posible limitación del derecho a la propiedad, no define a qué se refiere exactamente, sino que ofrece una serie de elementos que pueden ser enmarcados como constitutivos de dicha función social, los que han sido restrictivamente interpretados por el Tribunal Constitucional. El Tribunal Constitucional chileno ha sostenido en su jurisprudencia que el derecho a la propiedad sólo puede ser objeto de limitaciones cuando se ven afectados elementos de la función social establecidos por la Constitución. ${ }^{189}$ Además, cada uno de los elementos que pueden ser enmarcados como constitutivos de la función social han sido interpretados de manera restringida. Particularmente, la noción de interés general de la nación ha sido comprendida como "un bien jurídico que se relaciona directamente con la nación toda, entera, y jamás, por importante que sea, con un sector de ella, y que se relaciona, básicamente, con el beneficio superior de la sociedad política globalmente considerada, como un todo, sin referencia alguna a categorías o grupos sociales, económicos o de cualquier otro orden". 190

La actual Constitución establece otras disposiciones cuya interpretación ha restringido aún más la posibilidad de limitar la propiedad privada bajo la

\footnotetext{
188 Ibíd., pár. 34.

189 Tribunal Constitucional chileno, rol 334/2001, considerando 21.

190 Ibíd., considerando 22.
} 
noción de función social de la propiedad. Para ello, el artículo 19 N² 24 inc. 4 de la Constitución dispone que "Nadie puede, en caso alguno, ser privado de su propiedad, del bien sobre que recae o de alguno de los atributos o facultades esenciales del dominio, sino en virtud de ley general o especial que autorice la expropiación por causa de utilidad pública o de interés nacional, calificada por el legislador", solicitando una mayoría cualificada de senadores y diputados. Sin embargo, el artículo 19 N 26 establece que "La seguridad de que los preceptos legales que por mandato de la Constitución regulen o complementen las garantías que ésta establece o que las limite limiten en los casos en que ella lo autoriza, no podrán afectar los derechos en su esencia”. Así, cualquier política que involucre la privación de la propiedad, o de cualquiera de sus facultades esenciales, requiere la promulgación de una ley especial que debe ser aprobada por la mayoría de los senadores y diputados en ejercicio de sus funciones. También, cualquiera de las facultades del dominio, esto es, el uso, goce y disposición, han sido consideradas como atributos fundamentales del dominio que no pueden ser afectados por la ley. ${ }^{191}$

De esta manera, el derecho a la propiedad en el dogma constitucional chileno es tratado prácticamente como un derecho absoluto, sujeto sólo a algunas limitaciones legalmente establecidas bajo circunstancias restrictivas. Así, "las iniciativas que surjan del Estado para democratizar el uso del suelo se ven incesantemente frenadas por la dogmática jurídica de la propiedad”. ${ }^{192}$

Igualmente, la ex Relatora Especial sobre la vivienda adecuada, Raquel Rolnik, señaló que la "propiedad tiene una función social fundamental, en particular el derecho a una vivienda adecuada para los pobres de las zonas urbanas". 193 En este sentido, la nueva constitución chilena debe establecer que la función de vivienda es una parte esencial del contenido del derecho a la propiedad privada, mientras que los legisladores y agentes de políticas públicas deberían considerar explorar en el futuro distintas alternativas derivadas de la función social de la propiedad, tales como incentivos fiscales y sanciones a grandes empresas y/o dueños corporativos que deliberadamente mantengan propiedades vacías y fuera del mercado de arriendos residenciales.

\section{iii. Seguridad de la tenencia y criterios de habitabilidad en el sector de arriendos de viviendas}

En el contexto chileno, las políticas públicas sobre vivienda tienden a enfocarse en la propiedad, ${ }^{194}$ aunque en la última década el Estado introdujo

191 Ibíd., fundamento Jurídico Nº 25.

192 Alarcón et al., 2016, p. 111.

193 Asamblea General de Naciones Unidas, 2013, pár. 5(4).

194 Op. Cit., Asamblea General de Naciones Unidas, 2018, pár. 18. 
políticas públicas dirigidas a mejorar el déficit cuantitativo de la vivienda. Sin embargo, la legislación relativa al sector de arriendos privados no se ha sometido a reformas que protejan adecuadamente la seguridad de la tenencia y establezcan criterios de habitabilidad adecuada.

En este caso, la propiedad privada está protegida no sólo mediante un remedio constitucional de emergencia, sino también a través de regulaciones y otros instrumentos jurídicos. La ley Nº 18.101 de 1982, modificada en 2003, que establece reglas especiales sobre el arrendamiento de predios urbanos, dispone, en términos generales, que los propietarios pueden terminar el contrato de arrendamiento en cualquier momento, a menos que ambas partes acuerden lo contrario. Asimismo, la ley proporciona al arrendador un procedimiento abreviado para realizar desahucios.

En este sentido, las ordenes de desalojo en Chile son dictadas sin un análisis de razonabilidad y proporcionalidad, lo que es contrario a los estándares establecidos por el derecho internacional de los derechos humanos que han sido voluntariamente aceptados por Chile. La Relatora Especial de la ONU sobre la Vivienda Adecuada lamentó que, cuando un desalojo está a punto de realizarse en Chile, "el Estado no está obligado a velar porque se disponga de alojamiento alternativo ni a cumplir otras obligaciones internacionales de derechos humanos". ${ }^{195}$ Por lo tanto, después de su misión oficial de la ONU en el país, la Relatora Especial recomendó al Estado que las órdenes de desalojo deberían "realizarse en estricto cumplimiento del derecho internacional de los derechos humanos y no pueden dar lugar a la falta de hogar". 196

La legislación actual no establece una regulación específica que obligue al arrendador a mantener la vivienda bajo ciertos niveles de habitabilidad. A este respecto, el artículo 1924 del Código Civil sólo establece la norma general de que el arrendador debe mantener la propiedad en el estado de servir para el fin para el que ha sido arrendada; norma que es de aplicación cuando las partes no han acordado nada en otro sentido.

La falta de legislación conforme a los estándares del derecho internacional de los derechos humanos en el sector del arriendos privado, ha hecho posible el abuso de grupos particularmente vulnerables y de bajos recursos. En este sentido, los inmigrantes tienden a acceder a viviendas mediante contratos de arrendamiento; incluso aquellos que han llegado recientemente al país tienen un acceso informal e inseguro a la vivienda, con poca o ninguna protección de la ley. ${ }^{197}$ En un contexto como este, algunos inmigrantes han señalado ser "víctimas [de] prácticas abusivas en el mercado de vivienda privado por arrendadores que cobraban en exceso o que ofrecían condiciones de vida caras y

\footnotetext{
195 Ibíd., pár. 52.

196 Ibíd., pár. 86 (k).

197 Roessler et al., 2020, p. 1.
} 
precarias". 198 Así, en Chile "muchos migrantes viven en condiciones de hacinamiento, insalubres y antihigiénicas”. 199

La Relatora Especial de Naciones Unidas sobre la vivienda adecuada recomendó a Chile "Modernizar la legislación relativa a las viviendas de alquiler a fin de proteger mejor los derechos de los arrendatarios, y establecer una regulación adecuada de los arrendadores privados", 200 así como también "Asegurar la rendición de cuentas de los actores privados en relación con sus obligaciones de derechos humanos". ${ }^{201}$

El Comité de Derechos Económicos, Sociales y Culturales en 2015 y la Relatoría Especial sobre la Extrema Pobreza y Derechos Humanos en 2016 expresaron su preocupación sobre la falta de reconocimiento adecuado de los derechos económicos, sociales y culturales, incluyendo el derecho a una vivienda adecuada, en la Constitución de 1980; y sobre la falta de mecanismos institucionales y judiciales satisfactorios que provean remedios y reparaciones para las personas para quienes el derecho a una vivienda adecuada es una promesa incumplida. ${ }^{202}$

El Comité de Derechos Económicos, Sociales y Culturales presentó una lista de recomendaciones para hacer efectivo el derecho a la vivienda en Chile, con la visión de adoptar una estrategia integral de vivienda que diera prioridad a las personas más vulnerables, incluyendo aquellas viviendo en asentamientos informales, áreas rurales o condiciones inadecuadas; que protegiera contra desalojos forzosos y asignara financiamiento adecuado, con efectivo monitoreo y rendición de cuentas. ${ }^{203}$

En este sentido, la adopción de una estrategia comprehensiva es esencial. Un nuevo paradigma debería transitar desde la confianza ciega en el mercado privado de vivienda hacia un rol y compromiso activo del Estado en la provisión de viviendas. Más aún, un mo delo tal debe estar basado en el principio de que la adquisición de viviendas es una forma especial de propiedad privada sobre un bien que existe para servir una función pública que es al menos tan

198 Op. Cit., Asamblea General de Naciones Unidas, 2018, pár. 63.

199 Op. Cit., Asamblea General de Naciones Unidas, 2016, pár. 63.

200 Op. Cit., Asamblea General de Naciones Unidas, 2018, pár. 86 (j).

201 Ibíd., pár. 86 (n).

202 Comité de Derechos Económicos, Sociales y Culturales de Naciones Unidas, 2015, pár. 7; Op. Cit., Asamblea General de Naciones Unidas, 2016, pár. 25-26.

${ }^{203}$ Ibíd., Comité de Derechos Económicos, Sociales y Culturales de Naciones Unidas, 2015, pár. 26; Op. Cit., Asamblea General de Naciones Unidas, 2018, pár. 84. 
Chile tiene una oportunidad única de afianzar constitucionalmente el derecho a una vivienda adecuada. El silencio ensordecedor sobre la vivienda adecuada en la Constitución de 1980 ha contribuido al debilitamiento de este derecho en el orden doméstico en detrimento del pueblo chileno, particularmente de los hogares más vulnerables. Sería ingenuo pensar que adoptar una carta social constitucional asegurará su protección ${ }^{204}$ por sí sola, pero la consagración constitucional de los derechos sociales tiene un rol subsidiario, aunque de importante apoyo, en el esquema multiinstitucional de protección de los derechos sociales. ${ }^{205} \mathrm{El}$ momento constitucional único y profundamente democrático de Chile provee una excelente oportunidad para construir el derecho a una vivienda adecuada desde cero.

\footnotetext{
204 King, 2012, p. 2

205 Ibíd, p. 18.
} 
Alarcón, F. et al. (2016)

'Derecho a una vivienda adecuada en Chile: Una mirada desde los campamentos', en Vial, T. (rev.) Informe Anual sobre Derechos Humanos en Chile. Santiago, Chile: Universidad Diego Portales, pp. 81-121.

Asamblea General de Naciones Unidas (2013)

Informe de la Relatora Especial sobre una vivienda adecuada como elemento integrante del derecho a un nivel de vida adecuado y sobre el derecho de no discriminación a este respecto, Raquel Rolnik. Documento No. A/HRC/25/54.

Asamblea General de Naciones Unidas (2016)

Informe del Relator Especial sobre la extrema pobreza y los derechos humanos sobre su misión a Chile. Documento No. A/HRC/32/31/ Add.1.

Asamblea General de Naciones Unidas (2017) Informe de la Relatora Especial sobre una vivienda adecuada como elemento integrante del derecho a un nivel de vida adecuado y sobre el derecho de no discriminación a este respecto. Documento No. A/ $\mathrm{HRC} / 34 / 51$.

Asamblea General de Naciones Unidas (2018)

Informe de la Relatora Especial sobre una vivienda adecuada - Misión a Chile. Documento No. A/HRC/37/53/Add.1.

Bustos, R. (2015)

'Nueva constitución y derechos sociales: Hacia un nuevo paradigma', en Chía, E. y Quezada, F. (rev.) Propuestas para una nueva constitución (originada en democracia). Santiago: Fundación Igualdad, pp. 227-249.

Centro Europeo de Derechos de los Romaníes vs. Grecia (2004) Comité Europeo de Derechos Sociales. Reclamaciones Colectivas No 15/2003, Resolución de Fondo, 8 de diciembre.

Comisión de Estudio para una Nueva Constitución (1977)

Actas Oficiales de la Comisión de Estudio de la Nueva Constitución Política de la República. Sesión 281. Disponible en: https://obtienearchivo.bcn.cl/obtienearchivo?id=recursoslegales/10221.3/3768/2/ Tomo_IX_Comision_Ortuzar.pdf (Consulta: 28 septiembre 2020).

Comité de Derechos Económicos, Sociales y Culturales de Naciones Unidas (1991) 
Observación general $n^{\circ}$ 4: Derecho a una vivienda adecuada. Documento No. E/1992/23.

Comité de Derechos Económicos, Sociales y Culturales de Naciones Unidas (2015)

Observaciones finales sobre el cuarto informe periódico de Chile. Documento No. E/C.12/CHL/CO/4.

Comité de Derechos Humanos de Naciones Unidas (1988)

Observación general n 16: Artículo 17 (Derecho a la intimidad) El derecho al respeto de la intimidad, la familia, el domicilio, correspondencia y la protección a la honra y reputación. Documento No. ONU HRI/GEN/1/Rev.1 at 21.

King, J. (2012)

Judging social rights. Londres. Cambridge University Press, 3ra edición.

Ley de Vivienda de 1996,

Parte VII: Homelessness, modificada por Homelessness Reduction Act 2017.

Lovera, D. (2010) ‘

Derechos Sociales en la Constitución del 80 (... y del 89, y del 2005)', en Fuentes, C. (rev.), En nombre del pueblo: Debate sobre el cambio constitucional en Chile. Santiago: UDP and Fundación Böll, pp. 217243.

OCDE Data (sin fecha)

Income inequality. Disponible en: https://data.oecd.org/inequality/ income-inequality.htm (Consulta: 14 enero 2021).

Pérez Solano, J.A. (2016)

'Conceptualización de la función social de la propiedad en el derecho español y colombiano', Revista Jurídica Mario Alario D’Filippo, 8(16):176- 191

Private Housing (Tenancies) (Escocia) Ley 2016.

Roessler P. et al. (2020)

Acceso a la vivienda y condiciones de habilitabilidad de la población migrante en Chile. Santiago: Servicio Jesuita a Migrantes, Informe $N^{\circ}$ 3.

Schönsteiner, J. et al. (2016)

Conclusiones principales y recomendaciones estudio línea base en empresas y derechos humanos Chile. Encargado y financiado por: Instituto Danés de Derechos Humanos (DIHR). Santiago: Centro de 
Silva, I. et al. (2020)

Habitar en dignidad: hacia el derecho a la vivienda en la nueva Cons-

titución. Santiago: Techo-CHILE, Fundación Vivienda y GI-ESCR.

Social and Economic Rights Action Center (SERAC) and Center for Economic and Social Rights (CESR) vs. Nigeria (2002)

Comisión Africana de Derechos Humanos y de los Pueblos. Comunicación No. 155/96, Resolución del 27 de mayo.

Techo Mexico vs. INEGI (2020)

Suprema Corte de México. Amparo en Revisión 635/2019, Sentencia, 17 de junio.

Tribunal Constitucional de Chile (2001)

Sentencia 334/2001, 21 de agosto.

Tribunal Constitucional de España (2015)

Sentencia 93/2015, 14 de mayo.

Tribunal Constitucional de España (2018)

Sentencia 16/2018, 22 de febrero.

Tribunal Constitucional de España (2018)

Sentencia 32/2018, 12 de abril.

Vols, M., Kiehl, M. y Sidoli del Ceno, J. (2015)

'Human Rights and Protection against Eviction in Anti-social Behaviour Cases in the Netherlands and Germany', European Journal of Comparative Law and Governance, 2:156-181. 